\title{
Atividade fotoprotetora de extratos e frações de Lippia insignis
}

\section{Hismirllei Santana Lima ${ }^{1}$; Angélica Maria Lucchese ${ }^{2}$; Maíra Meira de Freitas ${ }^{3}$}

1. Bolsista PIBIC/CNPq, Graduando em Farmácia, Universidade Estadual de Feira de Santana, e-mail: hismirllei@gmail.com

2. Angelica Maria Luchese, Departamento de Exatas, Universidade Estadual de Feira de Santana, e-mail: angelica.lucchese@gmail.com

3. Maira Meira de Freitas, Universidade Estadual de Feira de Santana, e-mail: mairafreitas_s2@hotmail.com

PALAVRAS-CHAVE: fotoproteção; extratos, fracionamento.

\section{INTRODUÇÃO}

Existe uma analogia estrutural entre os filtros solares sintéticos e os princípios ativos de produtos naturais que possam apresentar uma ação fotoprotetora, como os flavonoides, uma vez que a absorção ultravioleta tem sido verificada quando se utiliza extrato vegetal em produtos farmacêuticos e cosméticos (RAMOS et al., 1996). Filtros solares são substâncias capazes de absorver, refletir ou refratar a radiação ultravioleta e assim proteger a pele da exposição direta da luz solar (GIOKAS et al., 2005). A atividade biológica de um protetor solar é avaliada por sua habilidade em proteger a pele de eritemas e edemas, reduzir o risco de queimaduras e o risco de carcinoma de células da camada basal e espinhosa (TOYOSHIMA et al., 2004).

Plantas do gênero Lippia são comumente usadas pela população para a cura de diversas enfermidades, destacam-se pelo aroma forte e agradável e seu aspecto atrativo no período de floração. Estudos comprovaram que algumas espécies desse gênero possuem principalmente ação antimicrobiana, antinociceptiva e anti-inflamatória (COSTA et al., 2002). Lippia insignis é um arbusto aromático nativo do Estado da Bahia, com distribuição na caatinga e cerrado (SALIMENA, MULGURA, 2014), com relatos de atividade antioxidante e presença de flavonoides (FREITAS, 2016). Assim o objetivo deste trabalho foi determinar a ação fotoprotetora de caules, folhas e inflorescências de Lippia insignis e fracionar o extrato do orgão mais promissor na busca de novos ativos.

\section{MATERIAL E MÉTODOS}

Atividade fotoprotetora - Para determinação do fator de proteção solar (FPS) foi utilizado o método espectrométrico desenvolvido por Mansur et al. (1986). A leitura da absorbância foi realizada em espectrofotômetro nos comprimentos de onda de 290 a 320 $\mathrm{nm}$, em intervalos de $5 \mathrm{~nm}$. O FPS foi calculado seguindo a equação FPS $=$ FC x $290 \Sigma$ $320 \operatorname{EE}(\lambda)$ x i $(\lambda)$ x Abs $(\lambda)$. O cálculo da razão UVA/UVB foi realizado para 
determinar a proporção entre a absorbância na faixa do UVA e na faixa do UVB, conforme equação a seguir:

$$
\frac{U V A}{U V B}=\frac{\int_{200 m}^{400 m} A \lambda \cdot d \lambda}{\int_{20 m}^{320 m} A \lambda \cdot d \lambda}
$$

A partir do resultado obtido por esta equação, ao protetor solar são conferidas estrelas classificando a sua ação anti-UVA, segundo tabela 1 (BOOTS THE CHEMIST LTD., 2008; VELASCO et al., 2011).

Tabela 1 - Relação do fator de proteção e eficiência UVA/UVB

\begin{tabular}{|c|c|c|}
\hline \multirow[b]{2}{*}{ Razão UVA } & \multicolumn{2}{|c|}{ Proteção AntiUVA } \\
\hline & Estrelas & Descrição ${ }^{a}$ \\
\hline 0,0 até $<0,2$ & - & Muito baixa \\
\hline 0,2 até $<0,4$ & * & Moderada \\
\hline 0,4 até $<0,6$ & \#* & Boa \\
\hline 0,6 até $<0,8$ & औた & Superior \\
\hline 0,8 até $<0,9$ & \#药 & Máxima \\
\hline$\geq 0,9$ & \#たたた & Ultra \\
\hline
\end{tabular}

Fracionamento químico - O fracionamento do órgão selecionado foi realizado por partição líquido-líquido. O extrato metanólico foi ressuspenso em metanol:água (7:3) e extraído com clorofórmio para obtenção das frações clorofórmica e hidrometanólica, com rendimento de $66,7 \%$ (10 g) e $26,6 \%$ (4 g), respectivamente.

\section{RESULTADOS E/OU DISCUSSÃO}

A atividade fotoprotetora consiste na capacidade de uma substância de bloquear a incidência da radiação ultravioleta (UV) em uma superfície, através da sua propriedade de reflexão ou de absorção dos raios solares nesta faixa de comprimento de onda. Os fotoprotetores orgânicos geralmente agem absorvendo radiação UV e dissipando em um comprimento de onda menos energético, mais longo, como o infravermelho (calor) e a luz visível (FLOR et al., 2007).

$\mathrm{Na}$ tabela 1, estão apresentados os Fatores de Proteção Solar (FPS's) das concentrações de 5 a $100 \mathrm{mg} / \mathrm{L}$ dos extratos brutos, que variaram entre 0,24 a 7,51. $\mathrm{O}$ mínimo valor de FPS determinado pela Anvisa é de 6, desta forma apenas os extratos de caules e folhas, na concentração de $100 \mathrm{mg} / \mathrm{L}$, atenderam a exigência, destacando-se o extrato de caules, com FPS de 7,51. Verificou-se para os extratos de todos os órgãos 
que há coerência entre o aumento da concentração e o da atividade fotoprotetora, demonstrando uma relação dose-dependente.

Tabela 1 - Fotoproteção dos extratos brutos de L. insignis expressa através do FPS

\begin{tabular}{c|c|c|c|c}
\hline Órgão & $\begin{array}{c}\text { FPS } \\
\text { Média } \pm \mathbf{D P} \\
\mathbf{5} \mathbf{~ m g} / \mathbf{m L}\end{array}$ & $\begin{array}{c}\text { FPS } \\
\text { Média } \mathbf{\pm D P} \\
\mathbf{2 5} \mathbf{~ m g} / \mathbf{m L}\end{array}$ & $\begin{array}{c}\text { FPS } \\
\text { Média } \pm \mathbf{D P} \\
\mathbf{5 0} \mathbf{~ m g / m L}\end{array}$ & $\begin{array}{c}\text { FPS } \\
\text { Média } \pm \mathbf{D P} \\
\mathbf{1 0 0} \mathbf{~ m g} / \mathbf{m L}\end{array}$ \\
\hline Caules & $0,36 \pm 0,03^{\mathrm{a}}$ & $1,84 \pm 0,05^{\mathrm{a}}$ & $3,74 \pm 0,06^{\mathrm{a}}$ & $7,51 \pm 0,19^{\mathrm{a}}$ \\
\hline Folhas & $0,27 \pm 0,01^{\mathrm{b}}$ & $1,48 \pm 0,09^{\mathrm{a}}$ & $3,20 \pm 0,09^{\mathrm{b}}$ & $6,48 \pm 0,12^{\mathrm{b}}$ \\
\hline Inflorescências & $0,24 \pm 0,06^{\mathrm{b}}$ & $1,19 \pm 0,07^{\mathrm{b}}$ & $2,42 \pm 0,12^{\mathrm{c}}$ & $4,83 \pm 0,11^{\mathrm{c}}$ \\
\hline
\end{tabular}

Médias seguidas pelas mesmas letras na coluna não possuem diferença significativa, segundo teste de Tukey $(\mathrm{p}<0,05)$ para comparação da média do FPS entre os órgãos; DP: desvio padrão.

Segundo a classificação Boot Stars Rating, razões de UVA/UVB acima de 0,9 são classificadas como ultraproteção, assim todas as amostras (tabela 2) apresentaram eficiência de ultraproteção frente à radiação UVA.

Tabela 2- Proteção anti UVA - Razão UVA/UVB

\begin{tabular}{l|l|l|l|l}
\hline \multirow{2}{*}{ Órgão } & $\begin{array}{l}\text { UVA/UVB } \\
\mathbf{5} \mathbf{~ m g / m L}\end{array}$ & $\begin{array}{l}\text { UVA/UVB } \\
\mathbf{2 5} \mathbf{~ m g / m L}\end{array}$ & $\begin{array}{l}\text { UVA/UVB } \\
\mathbf{5 0} \mathbf{~ m g} / \mathbf{m L}\end{array}$ & $\begin{array}{l}\text { UVA/UVB } \\
\mathbf{1 0 0} \mathbf{~ m g / m L}\end{array}$ \\
\hline Caules & 1,74 & 1,67 & 1,65 & 1,65 \\
\hline Folhas & 2,17 & 1,91 & 1,87 & 1,84 \\
\hline Inflorescências & 1,79 & 1,56 & 1,50 & 1,46 \\
\hline
\end{tabular}

Como o extrato de caule apresentou o melhor FPS entre os orgãos estudados, foi selecionado para fracionamento, com obtenção das frações clorofórmica e hidrometanólica, Na tabela 3 estão representados os Fatores de Proteção Solar (FPS's) das concentrações de 5 a $100 \mathrm{mg} / \mathrm{L}$, que variam de 0,15 a 4,55 na fração clorofórmica e de 0,26 a 6,57 na fração hidrometanólica. Apenas a fração hidrometanólica alcançou o valor mínimo de FPS exigido pela ANVISA (FPS =6) sugerindo assim que as substâncias bioativas estão localizadas nesta fração.

Tabela 3- Fotoproteção da fração clorofórmica do extrato metabólico bruto de caules de $L$. insignis expressa através do FPS

\begin{tabular}{c|c|c|c|c}
\hline CAULE & $\begin{array}{c}\text { FPS } \\
\text { Média } \pm \mathbf{D P} \\
\mathbf{5} \mathbf{~ m g} / \mathbf{m L}\end{array}$ & $\begin{array}{c}\text { FPS } \\
\text { Média } \pm \mathbf{D P} \\
\mathbf{2 5} \mathbf{~} \mathbf{~ g} / \mathbf{m L}\end{array}$ & $\begin{array}{c}\text { FPS } \\
\text { Média } \pm \mathbf{D P} \\
\mathbf{5 0} \mathbf{~ m g} / \mathbf{m L}\end{array}$ & $\begin{array}{c}\text { FPS } \\
\text { Média } \pm \mathbf{D P} \\
\mathbf{1 0 0} \mathbf{~ m g} / \mathbf{m L}\end{array}$ \\
\hline $\begin{array}{c}\text { Fração } \\
\text { clorofórmica }\end{array}$ & $0,15 \pm 0,02^{\mathrm{a}}$ & $1,04 \pm 0,33^{\mathrm{a}}$ & $2,256 \pm 0,45^{\mathrm{a}}$ & $4,454 \pm 0,95^{\mathrm{a}}$ \\
\hline $\begin{array}{c}\text { Fração } \\
\text { Hidrometanólica }\end{array}$ & $0,26 \pm 0,09^{\mathrm{a}}$ & $1,562 \pm 0,25^{\mathrm{a}}$ & $3,257 \pm 0,48^{\mathrm{a}}$ & $6,568 \pm 0,66^{\mathrm{b}}$ \\
\hline
\end{tabular}

Médias seguidas pelas mesmas letras na coluna não possuem diferença significativa, segundo teste de Tukey $(\mathrm{p}<0,05)$ para comparação da média do FPS entre os órgãos; DP: desvio padrão.

A relação UVA/UVB foi realizada também nas concentrações de 5 a $100 \mathrm{mg} / \mathrm{L}$ como representada na tabela 5 e ambas as frações podem ser classificadas com ação ultraprotetora. 
Tabela 4- Proteção anti UVA - Razão UVA/UVB

\begin{tabular}{c|c|c|c|c}
\hline Caule & $\begin{array}{c}\text { UVA/UVB } \\
\mathbf{5} \mathbf{~} \mathbf{g} / \mathbf{m L}\end{array}$ & $\begin{array}{c}\text { UVA/UVB } \\
\mathbf{2 5} \mathbf{~} \mathbf{g} / \mathbf{m L}\end{array}$ & $\begin{array}{c}\text { UVA/UVB } \\
\mathbf{5 0} \mathbf{~ m g} / \mathbf{m L}\end{array}$ & $\begin{array}{c}\mathbf{U V A} / \mathbf{U V B} \\
\mathbf{1 0 0} \mathbf{~ m g} / \mathbf{m L}\end{array}$ \\
\hline $\begin{array}{c}\text { Fração } \\
\text { clorofórmica }\end{array}$ & 0,93 & 1,39 & 1,08 & 1,38 \\
\hline $\begin{array}{c}\text { Fração } \\
\text { Hidrometanólica }\end{array}$ & 1,89 & 1,61 & 1,50 & 1,58 \\
\hline
\end{tabular}

\section{CONSIDERAÇÕES FINAIS}

O órgão mais promissor foi o caule com FPS de 7,51, que foi fracionado. Para a fração hidrometanólica obteve-se o melhor valor de FPS, indicando que as substâncias com ação fotoprotetora estão localizadas nesta fração. O perfil químico por CCD/CLAE e purificação das frações para isolamento das substâncias com ação fotoprotetora deverá ser conduzido.

\section{REFERÊNCIAS}

BOOTS the Chemist Ltd. The revised guidelines to the practical measurement of UVA/UVB ratios according to the Boots star rating system. The Boots Co. PLC, Notthingham; 2008.

BORES GARCÍA A. M . Lippia graveolens photochemopreventive effect against UVB radiation-induced skin carcinogenesis. J Photochem Photobiol B. 2017 Feb;167:72-81

BRASIL. Ministério da Saúde. Agência Nacional de Vigilância Sanitária. Resolução RDC N 30 de $1^{\circ}$ de junho de 2012. Aprova o Regulamento Técnico Mercosul sobre Protetores Solares em Cosméticos e dá outras providências. Diário Oficial da União, Brasília, 21 de ago. 2012.

FLOR, J.; DAVOLOS, M. R.; CORREA, M. A. Protetores solares. Química Nova, p. 153-158,2007.

FREITAS M.M. Composição química e atividade antioxidante de Lippia insignis moldenke. Seminário de iniciação científica-UEFS, 2016.

GONÇALVES, K. M, Assessment of the Photoprotective Activity of Lippia Species from Brazil and Their Use as Single UV Filters in Sunscreens Journal of Young Pharmacists, 2015; 7(4):368-372.

GUARATINI, T. et al. Fotoprotetores derivados de produtos naturais: perspectivas de mercado e interações entre o setor produtivo e centros de pesquisa. Química Nova, v. 32, n. 3, p. 717-721, 2009.

MANSUR, J. D. S. et al. Determinação do fator de proteção solar por espectrofotometria. Anais Brasileiros de Dermatologia, v. 61, n. 3, p. 121-4, 1986.

VELASCO, M. V. R. et al. Novas metodologias analíticas para avaliação da eficácia fotoprotetora (in vitro) - revisão. Revista de Ciências Farmacêuticas Básica e Aplicada, v. 32, n. 1, p. 27-34, 2011. 